\title{
Entrevista a Raúl Zibechi: "Los movimientos sociales son los únicos que pueden impedir la barbarización a la que nos conduce el sistema capitalista"
}

\author{
Lluís Català Oltra (Universitat d'Alacant) \\ José María Copete Fernández
}

Raúl Zibechi es un periodista y activista uruguayo, y un prolífico ensayista al que cuesta seguir el ritmo: veinte libros publicados, unos treinta y cinco capítulos en libros colectivos, gran cantidad de artículos, así como charlas y clases grabadas en video y subidas a las redes sociales... Ha colaborado en diversas publicaciones latinoamericanas como el diario mexicano La Jornada o el semanario uruguayo Brecha, y su militancia en los Tupamaros en los setenta le obligó a exiliarse. Asimismo, el alcance de su pensamiento ha motivado la aparición de libros y escritos de análisis sobre su obra o apoyados en ella. A pesar de todo, no le gusta definirse como un intelectual, pero está claro que Zibechi es un referente en el análisis de los movimientos sociales en América Latina y sus contextos sociales y culturales. Sus escritos están llenos de metáforas y referencias a la tierra y lo que emana de ella: 'arroyos', 'comunidades', 'desde abajo'... incluso de debajo de ella. Expresiones como 'las formas de pensamiento que emanan de nuestro subsuelo' indican un reconocimiento a las luchas por la emancipación económica o geopolítica, pero también un proceso de liberación epistemológico y cosmológico del eurocentrismo imperante y una puesta en valor de los saberes y las formas de pensamiento que afloran de las raíces de los pueblos indígenas, las comunidades campesinas, las barriadas periféricas y la gente sin poder que se organiza en resistencia frente a las formas de explotación y opresión a las que están sometidas. Esta puesta en valor, como él indica, ha de hacerse de manera crítica y sin idealizaciones, ya que estos saberes, como todos, pueden estar contaminados por múltiples sesgos.

Conversamos con Raúl Zibechi en su visita a la Universitat d'Alacant para dar un seminario de sobre movimientos sociales en la Facultad de Ciencias Económicas y Empresariales. En la charla previa a la entrevista comprendemos que Raúl es una persona que busca entender al interlocutor y aprender a través del diálogo allá donde vaya; nos pregunta, nos escucha con interés sobre cuestiones locales. No es de extrañar, por lo tanto, que sus análisis estén tan apoyados en la geopolítica y la información de alcance global como en retazos de vida cotidiana que se dan en la escala local, pero que alimentan de nuevo su visión global. En la entrevista le devolvemos la intención y profundizamos sobre todo en la situación de Latinoamérica.

José María Copete (JMC): Uno de tus últimos libros (Los desbordes populares desde abajo) aborda el ciclo de protestas que va desde 1959 a 1973 para el caso de América Latina, lo que en términos generales se denomina "mayo del 68”. ¿Por qué un libro sobre aquel período cinco décadas después?, ¿qué tenemos que aprender de aquella experiencia?

Raúl Zibechi (RZ): Bueno, primero porque cuando se habla de la "Revolución mundial del 68", en palabras de Wallerstein (1989), la mirada está demasiado centrada en París, cuando creo que fue un proceso global, que además se caracteriza por comenzar en la periferia para 
expresarse después en el centro. Concretamente arranca con la Revolución de Cuba, la independencia de Argelia, la Guerra de Vietnam... Incluso dentro de países como EEUU la protesta estudiantil contra la Guerra de Vietnam es precedida por la lucha por los derechos civiles, con aquel discurso de Martin Luther King, "I have a dream...", o la lucha del pueblo negro liderada por las Panteras Negras. Por tanto, me interesaba poner el acento en aquello que no estaba tan explícito en los estudios, en los periódicos, en el relato que se ha ido contando en estos cincuenta años, justo cuando se cumplían cincuenta años. Y me parecía que era importante hacer hincapié en dos cuestiones:

$1^{\circ}$ ) Que pasaron cosas bien importantes en la periferia del mundo, en este caso en América Latina, que fueron incluso causa de la respuesta represiva de los gobiernos. Por ejemplo, Chile era un país con un enorme movimiento popular: la mitad de Santiago cuando llega Allende al poder en 1970 eran campamentos de gente que había tomado tierras y estaba construyendo sus viviendas. Y esa potencia del movimiento popular me parecía que era importante reflejarla, porque fue común a muchas partes de América Latina. E incluso hubo corrientes de pensamiento asociadas muy potentes, como la teología de la liberación o la educación popular.

$2^{\circ}$ ) Porque en ese período se empiezan a ensayar construcciones territoriales ligadas a movimientos que después toman mucha fuerza: campesinos, indígenas (algunos de ellos sin tierra) y movimientos urbanos.

Creo que era importante exponer ambos temas. Cuando uno observa lo que pasó en un campamento famoso de Chile en los setenta, Nueva La Habana, donde coincidía mucha gente del MIR [Movimiento de Izquierda Revolucionaria de Chile], ve que había muchas construcciones que son las que ahora se están desplegando, a pesar de que eran muy pequeñas e incipientes. Eran construcciones en el terreno de la educación, de la salud, de la justicia incluso, que, de alguna manera, partieron de gente que no esperó que los Estados cubriesen determinadas carencias y las empezó a desarrollar desde abajo. En algunos casos de forma organizada y en otros de manera espontánea y desorganizada. En definitiva, son experiencias iniciales de movimientos populares que me parece que hay que recoger.

JMC: Me ha resultado interesante en tu libro precisamente la idea de "desborde popular desde abajo"...

RZ: El concepto de desborde no lo he acuñado yo, sino un antropólogo peruano en los años ochenta, José Matos Mar (1984), que tiene un trabajo muy interesante sobre cómo la migración andina fue un "desborde". ¿Qué se desborda? Bueno, se desborda la trama urbana, se desborda el panóptico como forma de control. Y eso también es universal, porque, por ejemplo, en Italia tuvimos la lucha antipsiquiátrica, liderada por Franco Basaglia (2013). Entre otras cosas, la idea del desborde es útil para comprender que también las izquierdas fueron desbordadas, que también las instituciones de la izquierda (sindicatos, partidos, etc.) fueron desbordadas. Y esta idea, vista desde dentro, desde quienes están desbordando, permite comprender una lógica que no es irracional; se proponen otras racionalidades que podemos compartir o no, pero que implican la autoconstrucción de sujetos que también, en segunda instancia, construyen ciudad, ciudadanía; que construyen, desde abajo y con otras lógicas, formas de vida alternativas respecto a las hegemónicas. Ese desborde modificó muchas cosas en América Latina. Incluso forzó a las izquierdas a reinventarse. Por ejemplo, el PT [Partido dos Trabalhadores] de Brasil es producto de esos desbordes, porque es el primer gran partido de América Latina que se 
construye desde abajo, a partir de los sindicatos (donde estaba Lula da Silva), pero también a partir de las comunidades eclesiales de base y de otras instancias. Los propios Sin Tierra empiezan también en esa época. Vemos la aparición de un nuevo sindicalismo, movimientos sociales nuevos, con fuerte arraigo territorial, que obligan, en cierta medida, a que las izquierdas estén en sintonía con eso que está pasando. Se produce entonces un diálogo muy fecundo entre la actividad social y las izquierdas. ¿Que luego han discurrido por diferentes caminos, como se ha podido ver con Lula y el PT? Eso es otra historia. Pero ubicados en ese período, desde los sesenta hasta incluso los ochenta, vemos una nueva configuración que va a ser muy productiva. El mismo PT, cuando llega a los primeros gobiernos municipales, implementa aquello que en su día fue muy importante, el presupuesto participativo, en el que la población, organizada en asambleas por barrios, podía modificar a qué se destinaban los recursos públicos, y dar prioridad a cosas que hasta ese momento no habían tenido atención por parte de los poderes públicos.

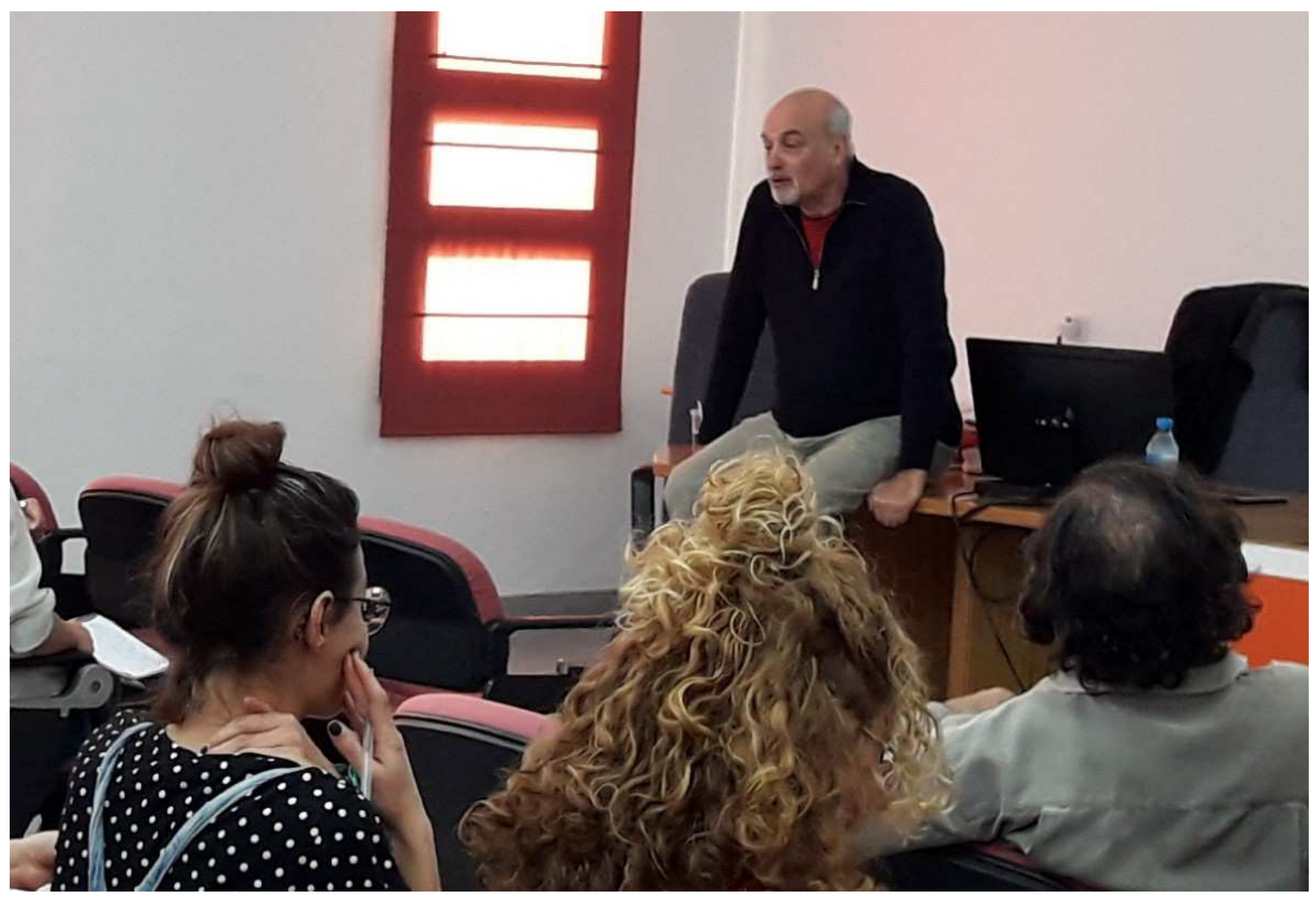

JMC: Respecto al libro Los arroyos cuando bajan: Los desafíos del zapatismo, del cual acaba de salir la segunda edición, ¿por qué comprender el zapatismo es importante para quienes aspiramos a una nueva sociedad?

RZ: Bueno, primero porque es un movimiento de nuevo cuño también. Es un movimiento que en los momentos iniciales debe corregir su rumbo, porque no hay que olvidar que quienes llegan a la selva Lacandona son militantes marxistas-guevaristas vanguardistas. Marcos, en una de las primeras entrevistas que concede, explica que tuvieron que hacer lo que los indígenas querían; 
éstos les dijeron: "aquí quien manda es la comunidad; si tú quieres reclutar a alguien de la comunidad para tu causa, es la comunidad quien toma las decisiones, no una persona individual". Entonces, hay una lógica, por decirlo de alguna manera, comunitaria, "no occidental" (en términos clásicos, porque eso también está transformándose en Europa), en la cual las vías de cambiar el mundo son otras, que no están muy definidas o demasiado claramente estipuladas, pero se van abriendo camino. Mi lectura es que, desde la Revolución Francesa y, sobre todo, desde la Comuna de París, la izquierda se ha dotado de una estrategia, que es la estrategia de la organización firme y férrea. Los partidos aparecen a partir de la Comuna para disputar el poder y desarrollar lo que se llama la "estrategia en dos pasos" (Wallerstein, 2002): conquistar el poder y luego transformar el mundo. Hace un siglo se consiguió por primera vez, en Rusia, y a lo largo de este siglo ha sido posible en varios países importantes, como China. En esas experiencias ha sido posible el primer paso, pero no el segundo. A mí modo de ver (y sé que esto es muy polémico, pero hay que plantearlo como un escenario de debate), esa estrategia está agotada; no es que no haya que tomar el poder, pero la estrategia está agotada. Y, entonces, los caminos que recorren los pueblos indígenas y, cada vez más, campesinos sin tierras y algunas periferias urbanas, en un diálogo virtual con las feministas, van en la línea de ir modificando nuestro lugar en el mundo, creando nuestros propios espacios y (aunque no me guste la palabra) "empoderándonos". En ese recorrido, quizá en algún momento sea posible desplazar del poder a quienes actualmente lo detentan, pero no nos organizamos exclusivamente para eso, porque en vez de una única estrategia hay como dos pies que caminan: se van creando espacios, poderes locales, y ya se verá si eso conduce a algo más.

Esto pasa en México, en el Estado de Oaxaca, por ejemplo, y no es casualidad, porque es un Estado con unos 500 municipios y, de ellos, unos 400 no se gobiernan por el resultado de las elecciones clásicas entre partidos, sino por "usos y costumbres": la asamblea de la comunidad decide quiénes van a ser alcaldes, por cuánto tiempo, si son renovados los que había, etc. Y el poder central de México lo tiene que aceptar y, de hecho, lo acepta. Los zapatistas lo que han hecho es que a los niveles "comunidad" y "municipio" han añadido otro más, "región", que es el que afecta a su influencia territorial. Aquí hay algo que podría ser denominado "estrategia" si ese término no remitiese a algo excesivamente pulido y terminado (no creo que lo sea). Sería más bien una búsqueda, un recorrido, en el cual la construcción de espacio o poder propio, no necesariamente está destinada a competir con el Estado ${ }^{1}$ (los zapatistas utilizan la bandera mexicana, por ejemplo), sino más bien a plantear alternativas a la de los "dos pasos".

Ése sería el fondo del tema, pero luego hay otras cosas que serían también interesantes, como, por ejemplo, que es un ejército que no usa armas. Han abandonado la idea de la revolución armada. Con esto de Marichuy [candidata zapatista y, por extensión del Congreso Nacional Indígena, a las elecciones presidenciales de 2018] y la campaña que han hecho, hay un paso importante ahí. Afirmaron que mientras sea posible no van a utilizar armas. Y si vienen, utilizarán el poder de la masa para frenarlos. Hasta ahora lo han conseguido, aunque nadie sabe si mañana puede haber un desastre tremendo. Es la apuesta que han hecho también otros pueblos indígenas de América Latina, particularmente los nasa del Cauca colombiano, que tienen una guardia indígena, elegida, igual que los zapatistas, por las comunidades. Cuando

\footnotetext{
${ }^{1}$ Salvo si el Estado agrede y en ese caso se defenderían.
} 
entran los paramilitares a su territorio reconocido constitucionalmente $\mathrm{y}$, por ejemplo, secuestran a alguien, van todos en masa con sus bastones de mando e intentan recuperarlos, a veces con éxito. Se busca defender el espacio, no confrontar con el otro. En la confrontación entienden que se pierde, porque tienen menos recursos, pero también porque la militarización jerarquiza. En la lucha por la emancipación, no quieren militarizarse. De hecho, después de 1994, los zapatistas no utilizaron más las armas. Las tienen, saben manejarlas, pero no las utilizan o, si lo hacen, sería sólo en última instancia. Es una apuesta ético-política y plantea también los límites de lo que fue en su día la militarización del campo revolucionario a partir de la guerra civil que vivió Rusia. El leninismo y después el stalinismo tomaron este camino dramático en el cual el Ejército Rojo terminó pareciéndose mucho al otro ejército, al zarista. No en vano, el Ejército Rojo, fundado por Trotsky, incorporó 30.000 oficiales zaristas a sus filas, para hacerlo más eficiente. Con esto, tienes finalmente un aparato que no puede ser muy emancipatorio...

Bueno, en definitiva, aquí hay un diálogo, que puede que no esté planteado todavía en los términos en los que yo he apuntado, pero por la vía de los hechos se va abriendo camino.

JMC: Respecto a la coyuntura actual de América Latina, a grandes rasgos, ¿puedes describirnos cuál es el papel que los movimientos populares pueden jugar?

RZ: Podría tener un impulso inicial de decirte "No tengo la menor idea", porque es un tema bien complejo, pero, sí hay que apuntar que:

$1^{\circ}$ ) Después de la intervención de Rusia, aliado de Siria e Irán, EEUU (junto a sus aliados Israel y Arabia Saudita) sufre un retroceso en Oriente Medio, y se ve obligado a irse de algunos frentes. EEUU también tiene problemas en el mar del Sur de China, donde no es fácil que mantenga la influencia que tenía, aunque no haya abandonado completamente. Y en su decadencia hegemónica, EEUU está obligado a reposicionarse con mucha fuerza en América Latina y, particularmente, en el Caribe (en México ya está muy bien posicionado). No pueden volver a sufrir lo que experimentaron en los embates de los últimos diez años de gobiernos progresistas de la región, especialmente el de Chávez en Venezuela, Correa en Ecuador y Evo Morales en Bolivia.

$2^{\circ}$ ) América Latina es un escenario de disputa entre las dos grandes potencias hegemónicas de hoy, China y EEUU, y los movimientos populares no harían bien, y no parecen que lo estén haciendo por ahora, en pegarse a alguna de las dos potencias hegemónicas. Ninguna de las dos es emancipatoria, aunque haya todavía compañeros de izquierda que China o incluso Rusia tienen un papel positivo, pero yo ahí comparto las posiciones de Santiago Alba Rico (2016), que creo que es muy lúcido, sobre todo cuando la guerra de Siria y la Primavera Árabe sus posiciones creo que son enteramente compartibles. Yo creo que los movimientos tienen que buscar una tercera opción. Creo que el zapatismo está en eso y también otros movimientos.

El principal problema al que se enfrentan los sectores populares en América Latina es el riesgo de una guerra civil en Venezuela, que hay que evitar a toda costa. Creo que no es apoyable Guaidó y toda la intervención extranjera que está habiendo, y no es apoyable Maduro. Creo que la militarización, el autoritarismo, la corrupción, apoyarse en las fuerzas armadas de forma demasiado marcada... Todo eso lleva a los movimientos a tener que buscar otro camino. Y en 
Venezuela son muy poquitos los que lo están buscando, pero hay quienes están en ello. Y en general, en América Latina, el principal problema que enfrentan los movimientos populares es el brutal avance de las derechas. Tienen que trabajar en espacios en los que hay una alianza entre los paramilitares, los narcos y las iglesias evangélicas, y Brasil es un claro ejemplo de ello. Es una alianza demencial, con mucha fuerza y que mueve dinero. Los movimientos están atrapados en este panorama y tienen enormes dificultades para mantenerse organizados. Los movimientos de los años noventa, por ejemplo, los Sin Tierra, que fueron muy fuertes, hoy están debilitados. Pero también hay que subrayar que está apareciendo un nuevo liderazgo de mujeres jóvenes. Todo el movimiento que acompañó y sigue acompañando el caso de Marielle Franco, ${ }^{2}$ que fue asesinada, está en esa línea y se mueve en ese escenario militarizado de gran dificultad. Hay un debate muy potente en los movimientos sobre si conviene que vuelvan gobiernos "progresistas" del estilo de Lula o Kirchner, si se defienden gobiernos como el de Evo Morales, o si hay que buscar un camino propio. Es una situación complicada y, salvo el movimiento de mujeres, que es el más importante hoy y está a la ofensiva, los demás están muy a la defensiva, porque el panorama deja poco margen de maniobra y las dudas son muchas.

Lluís Català (LC): En cualquier caso, ¿no crees que los movimientos sociales de América Latina están retados a posicionarse en el caso de Venezuela, a decantarse en algún sentido?

RZ: Sí, efectivamente, están retados a eso. Pero yo creo que ahí hay que diferenciar dos aspectos:

$1^{\circ}$ ) La intervención en Venezuela es intolerable, es un límite que no se debe pasar, y en ese sentido, hay que defender a Venezuela igual que se defiende a Cuba, independientemente de que estés o no de acuerdo con el régimen. Es una actitud de principios: la soberanía nacional es inviolable. Aquí no hay mucha duda, y creo que prácticamente todos los movimientos sociales de la región lo tienen claro.

$2^{\circ}$ ) El otro punto es el que plantea más duda y donde se está produciendo el debate entre quienes, además de defender la soberanía de Venezuela, defienden al régimen, y quienes son más críticos con el régimen o, como mínimo, no se pronuncian.

Esto último es un punto delicado. Una parte importante de las izquierdas latinoamericanas ha optado por el apoyo a Maduro, pero no todos los movimientos lo apoyan y son capaces de separar los dos puntos que he mencionado.

LC: Y en Bolivia, ¿tú crees que está al caer una situación análoga a la que se vive en Venezuela?

RZ: No. Tú vas a Bolivia y los supermercados tienen de todo, hay una relativa prosperidad, no es una situación económica boyante, pero sí razonablemente buena. La apuesta económica que ha hecho el gobierno de Evo [Morales] es muy distinta a la que hizo Chávez. Claro, Bolivia no tiene la mayor reserva de petróleo del mundo y eso condiciona mucho en el caso de Venezuela. En definitiva, en Bolivia la situación es muy distinta, incluso considerando que Evo puede perder las próximas elecciones. En Bolivia la situación de los sectores populares ha mejorado muchísimo bajo el gobierno de Evo.

2 Socióloga, feminista, concejala izquierdista de Rio de Janeiro, activista por los derechos de las mujeres negras de las favelas, fue asesinada a principios de 2018. 
LC: Es digno de destacar, porque Bolivia había sido siempre el país en peores condiciones de vida de Sudamérica. Ahora seguramente sea Venezuela, ¿no?

RZ: Sí, sin duda, es Venezuela, aunque en Ecuador y en Argentina las cosas tampoco andan muy bien, pero ésa ya es otra historia. En Bolivia no creo que se vaya a producir el tipo de confrontación que se está produciendo en Venezuela. Al menos aparentemente, aunque luego, claro, se puede dar una sucesión de acontecimientos que acaben en una situación catastrófica. En Bolivia, además, han tenido la inteligencia, aunque eso plantease dificultades desde el punto de vista ideológico, de hacer una alianza con la oligarquía terrateniente agroexportadora de Santa Cruz, que es la zona más rica y la que exporta todo el grano, soja, sobre todo, que se cultiva allí. Hay una agroindustria importante y el otro sector de explotación es la minería, pero está sobre todo en manos de multinacionales. Bolivia, en definitiva, ha sido otra experiencia totalmente distinta. Tampoco hay un intento, como sí hizo Chávez, de construir un poder popular, transitar hacia una economía nueva, expropiar una cantidad enorme de empresas extranjeras, amparados en ese monstruo, que es PDVSA [Petróleos de Venezuela, SA], la empresa estatal petrolera, que es inmanejable, lo era antes y lo sigue siendo ahora, aunque haya cambiado algo.

LC: Pasando a otro orden de cosas y saliendo quizá un poco del marco regional de América Latina, ampliando la visión a la escala mundial, Andrés Piqueras, aquí en España, le ha dado vueltas a las capacidades que tienen los sujetos colectivos de oponer un proyecto alternativo al del poder y sistema capitalista, quizá de momento con un horizonte algo sombrío. Ahora mismo, ¿ves tú algún resquicio por donde esto se pueda sustanciar o vamos directos a la barbarie?

RZ: Yo creo precisamente que los movimientos son los únicos que pueden evitar la barbarización. Dicho eso, también hay que decir que las experiencias alternativas con las que contamos en América Latina son más bien locales. Y en general, salvo algunas pocas, son experiencias de un tipo. Por ejemplo, puede haber buenas experiencias y de cierta dimensión de cultivos orgánicos. Y de éstas hay muchas, en México hay más de 2.000 experiencias entre pesca, miel, café... Pero suelen ser de una única cosa; son pocas las experiencias en las cuales hay un entramado de diversidad de producciones y, además, de salud alternativa, de educación alternativa, canales propios de comercialización... De eso hay muy poco: yo diría que algunos asentamientos Sin Tierra; el Movimiento Sin Tierra tiene entre 3.000 y 5.000 asentamientos, depende de cómo cuenten, pero que tengan una experiencia más de conjunto puede haber 100 , como mucho 200. También está la experiencia zapatista, que tiene bastante variedad, con bastante fuerza en salud y justicia, menos alternativa en educación. O están los nasa de Colombia, algunas experiencias argentinas con más de un producto y cierta organización, alguna en Bolivia, Paraguay, Perú... Pero hay que ser sinceros, aunque sean una alternativa y puedan serlo más claramente en un futuro, los movimientos hoy no lo están siendo y no hay una construcción de suficiente diversidad y alcance. Son un puñado de experiencias muy valiosas e interesantes, pero insuficientes para ser consideradas una alternativa en su conjunto al sistema. Más allá de los discursivo, claro, porque en lo discursivo todos podemos ser alternativos... 

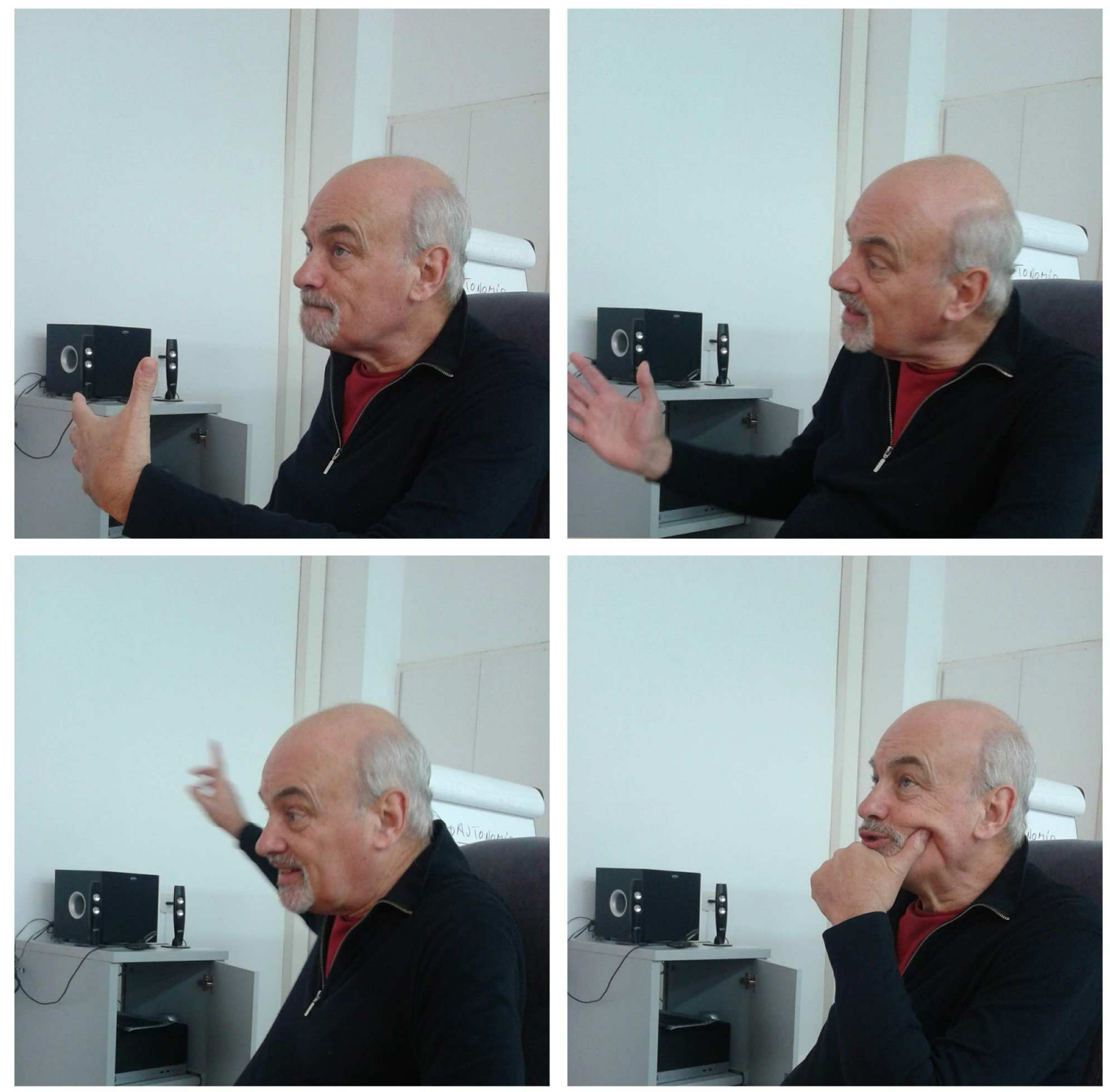

LC: Desde este punto de vista, si no hay una conexión más o menos rápida entre todas estas experiencias, y dando por hecho que el agotamiento del sistema es inminente (en lo ecológico, en lo referente a la capacidad del sistema de acumular valor, etc.), sí que podemos estar un poco al borde de la barbarización, ¿no? A no ser que haya una respuesta global rápida y contundente que no se ve asomar por ningún lado...

RZ: Cuando los zapatistas nos convocaron hace cuatro años a este encuentro que llamaron $L a$ hidra capitalista, nos decían a todos los que íbamos con nuestras ponencias: "Bueno, ustedes hagan de vigías y díganos qué es lo que ven en el horizonte". Efectivamente, vemos la tormenta que se aproxima, y frente a la gravedad de lo que viene y la escasez de lo construido para darle respuesta, queda claro que la dificultad está ahí, como ellos mismos planteaban. ¿Nos alcanzará el tiempo?, ¿nos alcanzará lo que hemos construido para sobrevivir a esto? Había un compañero de los que estaban allí en las mesas que, conversando, decía: “QQué pasará si mañana hay un colapso hídrico en una ciudad grande? La gente en masa se vendrá a nuestras comunidades, 
donde tenemos agua y recursos naturales. ¿Y qué hacemos?, ¿los rechazamos a tiros? Acogerlos a todos no podemos...". Y ese "¿qué hacemos?" me parece que es una pregunta bien interesante, porque lo que está diciendo es que hay un desfase entre la gravedad de la crisis sistémica (que no se sabe cuándo estallará definitivamente, pero que puede hacerlo) y lo que tenemos construido. Sí, estamos en un nivel de retraso enorme, quizá porque el desafío es muy grande. Y sobre eso, creo que hay poca conciencia. Uno puede leer el libro del colapso de [Ramón Fernández-Durán y] Luis González (2018) o el de Carlos Taibo (2017) u otros, y puede pensar: "el colapso vendrá en diez años, en cincuenta o lo que sea, pero es inminente"; al fin y al cabo, en el tiempo histórico, cincuenta años no son tantos. Y nosotros, ¿seremos capaces de construir arcas de Noé que nos permitan sobrevivir a esta tremenda situación? Hoy, yo diría que sobrevivirían nada más que un puñadito más pequeño aún que el de esas experiencias que he mencionado. Porque sí hay grupos que tienen esa variedad de construcciones, pero piensa sólo en el tema del agua: en Sao Paulo hay dos millones de habitantes que no tienen agua, y en Ciudad de México otro tanto. Podrías decir: "eso es sólo el 10\% o menos en el caso de México". Sí, pero tiene que ir todos los días un camión con el agua. Y el día que no va o que lo asaltan porque están desesperados por el agua, un montón de gente no la tiene. Es una muestra a pequeña escala de lo que puede suceder a escala planetaria. Por tanto, la cosa está complicada, y muy especialmente en las ciudades. Los movimientos campesinos o rurales tienen otras posibilidades, otros recursos. Aquí mismo, en Alicante o en Valencia, si la cosa se complicase, en el entorno rural seguramente habría más capacidad para subsistir...

\section{LC: Sí, lo único es que no hay apropiación colectiva de nada...}

RZ: Claro, y las multinacionales sí que tienen mapeadas las fuentes de agua, y las van comprando, si no las han comprado ya en su mayoría. Entre las clases dominantes y los sectores populares organizados en movimientos, hay un desfase muy fuerte.

LC: Hace cosa de un año viniste también a Alicante y pudimos oírte ambos en una charla. Ahí comentaste que el gran movimiento social actual podía ser el movimiento feminista, ¿qué elementos apoyan esta afirmación?

RZ: Bueno, primero porque es un movimiento muy activo, muy creativo, que ha sido capaz de llegar donde ha llegado sin tutelas de partidos, ni de Estados... Se podría decir que es un movimiento que tiene autonomía, porque involucra a una generación muy joven, muchas de ellas son chicas de alrededor de veinte años, que se manifiestan en su cotidianeidad con una potencia muy grande. Y luego están siendo capaces de poner en cuestión el patriarcado en muchas de sus manifestaciones, no sólo el machismo y la violencia. Es un movimiento que está subiendo enormemente, pero todo lo que sube suele bajar; no pueden convocar indefinidamente cada año el doble de manifestantes que el año anterior. Entonces el gran desafío es lo que pase cuando el movimiento baje. Ése será el momento clave, el momento en que hará falta plantearse objetivos y estrategias, quizá no muy ambiciosos, pero sí más allá de lo inmediato, más allá de la violencia que sufren, más allá del 8 de marzo... Y es ahí donde entramos en el mismo problema que comentábamos antes para los movimientos sociales. Yo creo que, de alguna manera, y no le estoy queriendo dar línea a nadie, el movimiento feminista va a terminar territorializándose, arraigando en espacios físicos donde las mujeres, ya en sus grupos, comiencen a trabajar con otros actores en la generación de espacios propios. Pero también puede pasar lo que pasó con una parte mayoritaria del movimiento gay, que terminó siendo 
atrapado por el mercado y, en cierta medida, también por el Estado. Eso pasó en mi país [Uruguay] y lo he visto también en otros países. Ha acabado siendo un movimiento que reivindica el matrimonio gay y pocas cosas más, y ha acabado muy dependiente de otras lógicas que no son la lucha antisistémica. Ese tipo de cosas pueden pasar, los movimientos pueden caer fácilmente en la lógica del sistema. Esperemos que no sea así.

JMC: En tu obra, haces análisis que tienen en cuenta la perspectiva global, pero sobre todo la perspectiva local. Utilizas muchos sinónimos y conceptos que vienen a significar la relación con la tierra, el territorio, arraigarse, comunidad, incluso subsuelo ("formas de pensamiento que vienen del subsuelo"), todos ellos conceptos que indican territorialidad, localidad. Frente a esto, o al mismo tiempo que esto, me gustaría que nos comentases qué papel crees que va a jugar o está jugando Internet en los movimientos populares, teniendo en cuenta que Internet, de alguna manera, modifica lo local, rompe las fronteras de la propia comunidad.

RZ: Estoy tentado de contestarte como Zhou Enlai [primer ministro de la República Popular China bajo la presidencia de Mao Zedong] respondió a un periodista que le preguntaba: “¿Qué balance hace de la Revolución Francesa?" y Zhou Enlai, buen chino y buen provocador, le dijo "Es demasiado pronto para saberlo". Bueno, llevamos poco tiempo con Internet, veinte años o poco más. Evidentemente hay un cambio e Internet ha sido un multiplicador, un conector importante de sensibilidades, de convocatorias... de muchas cosas. No me imagino o no me quiero imaginar un mundo en el cual los poderes lleguen a limitar el uso de Internet de tal forma que sus posibilidades se agoten. Pero eso hay que tenerlo en cuenta. Finalmente, Internet no lo controlamos nosotros. Ya hay una experiencia tremenda en China, país donde tú no puedes navegar por cualquier página y además están desarrollando su propia red. En China tienen prohibido entrar a cierto tipo de páginas, entre las cuales la pornografía, pero también otras que implican la limitación de la libertad de expresión. En Occidente no está tan limitada, pero también. Uno cuando habla con Richard Stallman [fundador del movimiento del software libre] se entera de que hay filtros y límites que desconocemos. En cualquier caso, si no llegara a producirse esa tremenda limitación, hay quien dice que la Revolución Francesa es hija de la imprenta; Gutenberg jugó un papel sin quererlo en la Revolución Francesa, porque las ideas impresas volaban ya a la velocidad de las carrozas, y probablemente Internet pueda llegar a jugar un papel similar. Puede permitir y, de hecho, ya está permitiendo, que ideas, que surgen en las ciudades, como esto del feminismo, vuelen a un pueblo remoto de la sierra, y no en el tiempo en el que lo hacían antes, que eran meses y años, sino en días. Por tanto, esa modificación de lo local que tú apuntas, tiene que ver con la velocidad y la aceleración de la experiencia histórica. Eso lo trabaja Giovanni Arrighi en el libro Adam Smith en Pekín (2007). Hay una aceleración del tiempo social histórico, y procesos que, insisto, antes demoraban años en ser comprendidos y asimilados lejos del epicentro, hoy llegan muy rápido. Eso, por un lado, es muy bueno, porque permite que el movimiento social se multiplique, pero tiene problemas también, porque a veces las cosas llegan de forma crítica. En alguna medida, Bolsonaro ganó las elecciones de Brasil por las redes sociales, supo usarlas muy bien. Y aquí en España, Ciudadanos y Vox parece que también lo están haciendo bien, con equipos destinados a eso. Hay cambios evidentes, pero no todos para bien. Desde lo que a nosotros nos interesa, que son los movimientos sociales, brinda posibilidades que antes no existían, está claro.

LC: Para terminar, ¿en qué sentido dices en alguna de tus obras que los movimientos pueden actuar como sujetos anticoloniales? 
RZ: Sin remontarme a Fanon (1963) y la lucha anticolonial, lo que yo veo, por lo menos en América Latina, tiene que ver con esta recolonización del planeta que está haciendo el capital, y que es a lo que hace referencia Harvey (2005) con su "acumulación por despojo". El análisis de Harvey, que yo comparto, llevado a las zonas de pobreza, tanto en la periferia como en las bolsas existentes en países centrales, se vive como una guerra, como una agresión. Los zapatistas hablan de Cuarta Guerra Mundial, en vez de acumulación por despojo, que me parece que es lo que vive un pueblo indígena. Y si lo trasladas a la especulación del ladrillo, que es lo más parecido en el Estado español, ves como a algunos habitantes de las periferias se sienten agredidos. Errekaleor, que es la experiencia de Vitoria-Gasteiz en la que se ocupan unas viviendas de un barrio obrero que iban a ser demolidas para crear una zona de ampliación nueva (ver Pérez, 2017), es una de tantas respuestas a todo esto. Las personas afectadas por la acumulación por despojo tienen un color de piel distinto, una situación estructural distinta, etc. En síntesis, quiero entender que este revival de Fanon y el anticolonialismo tiene que ver con la etapa actual, más depredadora, de acumulación del sistema capitalista.

\section{Bibliografía surgida en conversación}

Alba, S. (2016). Alepo, la tumba de la izquierda. Contexto, 95. https://ctxt.es/es/20161214/Firmas/10137/santiago-alba-rico-alepo-eeuu-israel-Putingeopolitica.htm (visita el 17-3-2019).

Arrighi, G. (2007). Adam Smith en Pekín. Orígenes y fundamentos del siglo XXI. Madrid: Akal.

Basaglia, F. (2013). La condena de ser loco y pobre. Alternativas al manicomio. Buenos Aires: Topía.

Ejército Zapatista de Liberación Nacional (2015). El pensamiento critico frente a la hidra capitalista I. Participaciones de la Comisión Sexta del EZLN. México: Ediciones Mexicanas. http://geopolitica.iiec.unam.mx/sites/default/files/2018-11/Hidra-EZLN.pdf (visita el 24-32019).

Fanon F. (1963). Los condenados de la tierra. México: Fondo de Cultura Económica. http://www.lahaine.org/b2-img09/fanon_condenados.pdf (visita el 24-3-2019).

Fernández-Durán, R. y L. González-Reyes (2018). En la espiral de la energía (volumen II). Colapso del capitalismo global y civilizatorio. Madrid: Libros en Acción ( $2^{\mathrm{a}}$ edición revisada). https://spip.ecologistasenaccion.org/IMG/pdf/en-la-espiral-de-la-energia_vol-2.pdf (visita el 24-3-2019).

Franco, M. (2017). A emergência da vida para superar o anestesiamento social frente à retirada de direitos: o momento pós-golpe pelo olhar de uma feminista, negra e favelada. En VVAA, Tem saída? Ensaios críticos sobre o Brasil. Porto Alegre: Zouk, 89-95. http://www.cedefes.org.br/wp-content/uploads/2018/03/Capitulo-MarielleFranco.pdf （visita el 17-3-2019). 
Harvey, D. (2005). El "nuevo imperialismo": acumulación por desposesión. Socialist Register 2004: El nuevo desafio imperial, 40, 99-129. https://socialistregister.com/index.php/srv/article/view/14997/11983 (visita el 24-3-2019).

Matos, J. (1984). Desborde popular y crisis del Estado. El nuevo rostro del Perú en la década de 1980. Lima: Instituto de Estudios Peruanos.

Pérez, I. (2017). Errekaleor. Reiniciando un mundo mejor. Libre Pensamiento, 92, 58-63. http://librepensamiento.org/wp-content/uploads/2018/02/LP-92.pdf (visita el 24-3-2019).

Piqueras, A. (2017). La tragedia de nuestro tiempo: la destrucción de la sociedad y la naturaleza por el capital. Análisis de la fase actual del capitalismo. Madrid: Anthropos.

Stallman, R. M. (2004). Software libre para una sociedad libre. Madrid: Traficantes de Sueños.

Taibo, C. (2017). Colapso. Capitalismo terminal, transición ecosocial, ecofascismo. Buenos Aires: Libros de Anarres. http://www.fondation-besnard.org/IMG/pdf/taibo_-_colapso_final1.pdf (visita el 24-3-2019).

Wallerstein, I. y S. Zukin (1989). 1968, revolution in the World-System: theses and queries. Theory and Society, 18 (4), 431-449.

Wallerstein, I. (2002). New revolts against the system. New Left Review, 18. https://newleftreview.org/II/18/immanuel-wallerstein-new-revolts-against-the-system (visita el 17-3-2019).

Zibechi, R. (2018). Los desbordes desde abajo. 1968 en América Latina. Bogotá: Eds. Desde Abajo.

Zibechi, R. (2019). Los arroyos cuando bajan: Los desafíos del zapatismo. Vitoria-Gasteiz: Zambra-Baladre ( $2^{\mathrm{a}}$ edición). 